\title{
Investigations at High Temperature in Both Equilibrium and Kinetic State with Knudsen Effusion Mass Spectrometry (KEMS) and a Skimmer Integrated Coupling System of Mass Spectrometer and Thermal Analysis (STAMS)
}

\author{
Dietmar Kobertz ${ }^{1, *}$, Christo Guguschev ${ }^{2}$ and Michael Müller ${ }^{1}$ \\ ${ }^{I}$ Institut für Energie- und Klimaforschung, Forschungszentrum Jülich GmbH, Germany \\ ${ }^{2}$ Leibniz-Institut für Kristallzüchtung, Max-Born-Str. 2, 12489 Berlin, Germany
}

\begin{abstract}
Research on materials at high temperatures under equilibrium as well as under kinetic conditions poses a high challenge for any scientist. The investigations of the properties are limited either by the sample holding container or by the instrumentation that should analyze the significant information. Thermodynamic investigation in equilibrium state with the Knudsen effusion mass spectrometer (KEMS) and thermal analysis (DTA/TG/DSC) in quasi equilibrium state at temperatures beyond $1000^{\circ} \mathrm{C}$ are main and standard topics in our lab.

This article will introduce measurements on aluminum nitride (AIN) as a potential material for application in microelectronics, electronic substrates, chip carriers where high thermal conductivity is essential, and light emitting diodes (LED).
\end{abstract}

Keywords: Knudsen Effusion Mass Spectrometry (KEMS), thermochemistry, high temperature, vaporization, aluminum nitride, AlN.

\section{INTRODUCTION}

The knowledge of the vaporization behavior is an important property in materials research either under kinetic or under equilibrium conditions. Kinetic orientated vaporization is strongly dependent on material conditions like surface structure, atmosphere surroundings et cetera while vaporization in equilibrium conditions really allows to describe the material at different states. Only in equilibrium it is possible to see the difference between a start-state and an end-state on changing the energy situation in a system and that the path to go from one state to the other state is arbitrary; and that is exactly the characteristic of a statefunction in thermodynamics.

On the way to obtain these information, one needs a tool that allows to produce an equilibrium state of the material with its surrounding, to change the energy state of this system from one state to another, and one must have a possibility to analyze all the given species in the vapor phase over this material. Exactly these specifications can be fulfilled in a Knudsen Effusion Mass Spectrometer (KEMS)

Material in equilibrium state undergoes mostly kinetic orientated processes during short-time applications and the standard state properties are no more valid. A typical example describing this situation is the combustion of brown

*Address correspondence to this author at the Institut für Energie- und Klimaforschung, Forschungszentrum Jülich GmbH, Germany;

Tel: +492461615769; Fax:+492461618313; E-mail: d.kobertz@fz-juelich.de or hard coal and even biomass in a fossil power plant. Biomass, as a modern energy source, gets its local system equilibrium state during growing. The formation of coal has reached an equilibrium state in thousands of years and in a short time it changes its constitution during combustion in order to end in form of energy and as ash, slag and deposits in the power plant. Educts and products can be analyzed quite easily in terms of element constitution and equilibrium state properties, but what is happening during the combustion?

Answers to this question can be found with a skimmer coupled mass spectrometer that is able to analyze in situ the vapor phase containing both condensable and noncondensable gas species. An advanced version of a skimmer mass spectrometer is a version coupled with a thermal analyzing system that allows simultaneously analyzing both the condensed and the vapor phase.

The skimmer coupling system with a quadrupole mass spectrometer (STAMS) used in our lab is a very sensitive system for thermo analytical gas analysis. The coupling takes place directly in the furnace and is arranged right above the sample container. Since the entire system has sample temperature, no condensation during the gas emanation changes the condition of the vapor phase of the sample.

\section{BACKGROUND}

Aluminum nitride single crystals have several advantages over sapphire and silicon carbide as substrates employing $\mathrm{Al}_{\mathrm{x}} \mathrm{Ga}_{1-\mathrm{x}} \mathrm{N}$ epitaxial layers for electronic and optoelectronic 


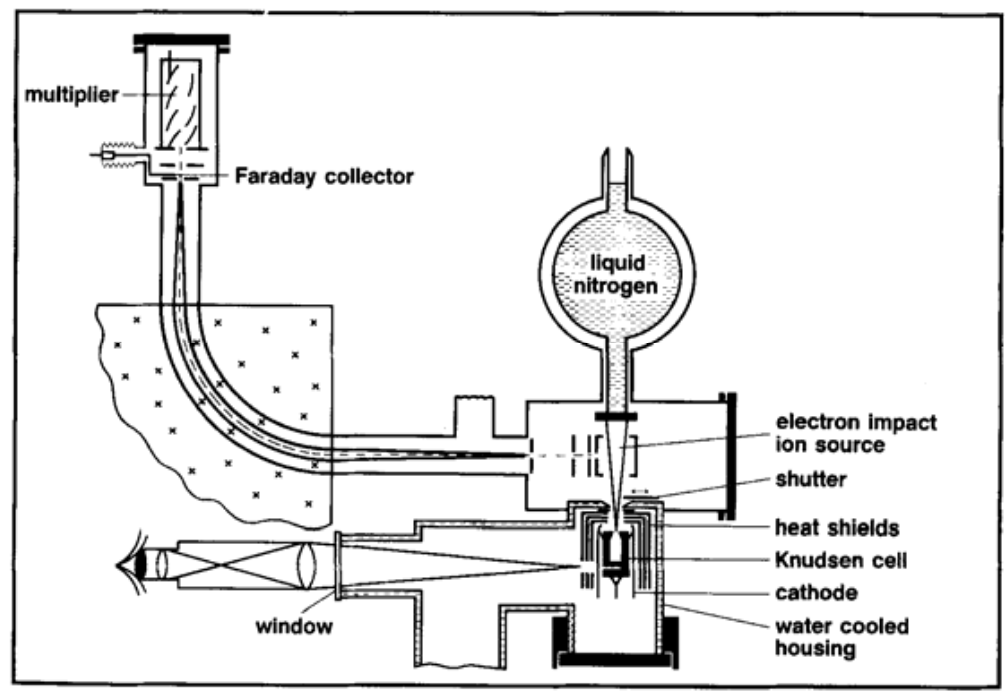

Fig. (1). Schematic representation of the Knudsen cell-mass spectrometer system using a single-focusing magnetic type sector-field instrument.

devices [1-5]. The thermal conductivity of aluminum nitride $(3.2 \mathrm{~W} / \mathrm{cmK})[6]$ is $6-7$ times higher than that of sapphire; thus AlN is better at dissipating heat generated by devices. Aluminum nitride has the same crystal structure (i.e. wurtzite) as all compositions of $\mathrm{Al}_{\mathrm{x}} \mathrm{Ga}_{1-\mathrm{x}} \mathrm{N}$, thus epitaxy in any crystal orientation should be possible. Since AlN has the smallest lattice constant mismatch with $\mathrm{Al}_{\mathrm{x}} \mathrm{Ga}_{1-\mathrm{x}} \mathrm{N}$, it may be possible to prepare epitaxial layers without any high dislocation density buffer layer.

Reducing the density of dislocations will improve the efficiency of light emitting diodes, especially those emitting at wavelengths shorter than 280nm. Mymrin et al. [7] predicted that reducing the dislocation density will increase the external quantum efficiency of UV LEDs by two orders of magnitude. Such an increase in efficiency would help to make $\mathrm{Al}_{\mathrm{x}} \mathrm{Ga}_{1-\mathrm{x}} \mathrm{N}$ UV-LEDs commercially practical.

Typical condition for the formation of Aluminium nitride (AlN) of $\mathrm{T}>2000{ }^{\circ} \mathrm{C}, 400-1000$ mbar $^{N_{2}}$ pose a high challenge in terms of parameter adjustment for single crystal growth and analytical requirement of gas phase transport (Physical Vapor Transport, PVT). Till now there are controversial discussions in literature about the actual chemical cycle since no experimental data are available.

The classical model of sublimation - recombination of AlN following the equation

$\operatorname{AlN}(\mathrm{s}) \leftrightarrow \mathrm{Al}(\mathrm{g})+1 / 2 \mathrm{~N}_{2}(\mathrm{~g})$

is probably oversimplified. Some models describe and suppose different $\mathrm{Al}_{\mathrm{x}} \mathrm{N}_{\mathrm{y}}$ gaseous molecules being determinant for crystal growth [8]. Beside this, intrinsic contaminations are known as disturbing factors in the gas phase processes. Oxygen for example affects the properties, crystal quality, and surface morphology of the AIN crystals. Edgar et al. [9] pictures the implication of oxygen and hydroxides on the crystal growth of bulk aluminium nitride. The problems associated with the growth of high purity crystals of AIN are reviewed in an article by Slack et al. [10]. The impurities $\mathrm{Be}, \mathrm{C}, \mathrm{Mg}, \mathrm{Mn}, \mathrm{O}, \mathrm{S}$, and $\mathrm{Si}$ are discussed.
To understand the conditions in forming of $\mathrm{AlN}$, the knowledge of the vaporization behavior is an important property. The Knudsen Effusion Mass Spectrometry (KEMS) is one of the most powerful tools to analyze the vapor phase in equilibrium state and to determine the partial pressures of the species in a pressure range $10^{-14}-10^{-4}$ bar and temperatures up to $3000 \mathrm{~K}$. Thermodynamical data achieved from these studies, like enthalpy $(\Delta \mathrm{H})$, entropy $(\Delta \mathrm{S})$, chemical activities $(\mathrm{a})$, and equilibrium constants $\left(\mathrm{K}_{\mathrm{p}}\right)$ allow to predict the system properties concerning both the condensed and vapor phase. Due to the limited Knudsen condition at an upper pressure of $10 \mathrm{~Pa}$ the studies were terminated at $\sim 1520^{\circ} \mathrm{C}$

Our measurements on AIN single crystals vaporization were realized in the temperature range between $1300^{\circ} \mathrm{C}$ and $1500{ }^{\circ} \mathrm{C}$. The vapor phase was analyzed and the ions $\mathrm{Al}^{+}$, $\mathrm{N}_{2}{ }^{+}, \mathrm{N}^{+}, \mathrm{O}_{2}{ }^{+}, \mathrm{O}^{+}, \mathrm{Al}_{2}{ }^{+}$and $\mathrm{Al}_{2} \mathrm{O}^{+}$were registrated in the mass spectrum as representatives of the gas species over AIN. These species are established in equilibrium state, but they need not to be the only species in a kinetic orientated state. The process conditions of the formation of $\mathrm{AIN}\left(\mathrm{T}>2000{ }^{\circ} \mathrm{C}\right.$, $\left.\mathrm{p}\left(\mathrm{N}_{2}\right) \sim 600 \mathrm{mbar}, \Delta \mathrm{T}<5 \mathrm{~K} / \mathrm{cm}\right)$ differ strongly from the Knudsen measurement equilibrium conditions. For the analysis of the gaseous phase outside of the Knudsen conditions it was needed to design a mass spectrometer that allows an in-situ extraction of condensable and noncondensable vapor species out of the AIN crystal growth process surrounding. The construction of this tungsten-based skimmer coupled mass spectrometer has just started (see section Skimmer MS, and Fig. 5).

Measurements with a commercial skimmer coupled instrument in the temperature range of the KEMS studies were done to see reactions in the vapor phase under the influence of kinetic orientated processes in comparison to those in the equilibrium state.

\section{EXPERIMENTAL}

The principle setup of a KEMS is shown in Fig. (1). It consists of a single-focusing magnetic type sector-field mass 
spectrometer, an electron impact ion source, a Knudsen cell and a collector arrangement of multiplier and Faraday cup. A cryogenic pump filled with liquid nitrogen reduces the background in the ion source. Ion pumps generate the ultrahigh vacuum in the mass spectrometer; and a turbo molecular pump is used for the Knudsen cell chamber. This chamber can be separated from the mass separator by a valve, a so-called shutter that is further used as a beam suppressor.

A fast and precise mass adjustment is possible by the use of a Hall probe supported magnetic field controller and a mass programmer. The mass peak scan is done by sampling the accelerating voltage in a small range sufficient enough to cover some peak widths in the mass range of interest. More details of the instruments are given in Refs [10] and [11]. The mass spectrometer type used in our labs have been modified substantially by us with things like installing an ion counting arrangement or a computer controlled heating and mass scanning.

\section{PRINCIPLE OF THE METHOD}

Real thermodynamic equilibrium can only be fulfilled in a closed system. The Knudsen cell is a quasi closed system since it has a very small effusion orifice (typical diameter: 0.1-1 mm) through which a small fraction of molecules effuse practically without disturbing the equilibrium in the cell and since the mean-free path of the molecules is much longer than the dimension of the orifice. Fundamentals are given in Refs. [12-17].

A molecular beam representing the equilibrium vapour in the cell is formed by the effusing species. This molecular beam crosses the electron ionization source where ions are formed by electron impact in principle after equation (1)

$\mathrm{A}(\mathrm{g})+\mathrm{e}^{-}=\mathrm{A}(\mathrm{g})^{+}+2 \mathrm{e}$

Different other impact reactions producing molecule ions and fragments of molecules will give helpful fingerprints to understand the gaseous phase. The ions are accelerated and than mono-energetically entering the mass analyser where they are separated by their mass to charge ratio (m/e). After separation the collectors register the ion and the obtained intensities are proportional to the quantity of atoms or molecules present in the vapour. From the ion intensities partial pressures can be determined with equation (2)

$\mathrm{p}(\mathrm{i})=\mathrm{k}$ I(i) $\mathrm{T}$

with $\mathrm{k}$ as an instrument constant, I(i) as ion intensity, $\mathrm{T}$ as absolute temperature.

The equilibrium state of the system allows formulating a constant related to the pressures (equ. (3))

$\mathrm{K}_{\mathrm{p}}=\Pi\left[\mathrm{p}(\mathrm{i}) / \mathrm{p}^{\circ}\right]^{\mathrm{x}(\mathrm{i})}$

with $\mathrm{p}(\mathrm{i})$ is partial pressure of species $i, \mathrm{p}^{\circ}$ is standard pressure, and $\mathrm{x}(\mathrm{i})$ is the stoichiometric coefficient of species $i$ that describes vaporization reactions such as:

$\mathrm{A}(\mathrm{s})=\mathrm{A}(\mathrm{g})$ with the equilibrium constant $\mathrm{K}_{\mathrm{p}}=\mathrm{p} / \mathrm{p}^{\circ}(\mathrm{A})$ or

$\mathrm{AB}(\mathrm{s})=\mathrm{A}(\mathrm{g})+\mathrm{B}(\mathrm{s})$ with $\mathrm{K}_{\mathrm{p}}=\mathrm{p} / \mathrm{p}^{\circ}(\mathrm{A})$

or the dissociation reaction:
$\mathrm{AB}(\mathrm{g})=\mathrm{A}(\mathrm{g})+\mathrm{B}(\mathrm{g})$ with $\mathrm{K}_{\mathrm{p}}=\mathrm{p} / \mathrm{p}^{\circ}(\mathrm{A}) \mathrm{p}(\mathrm{B}) / \mathrm{p}(\mathrm{AB})$

or the dimerization:

$2 \mathrm{~A}(\mathrm{~g})=\mathrm{A}_{2}(\mathrm{~g}) \quad$ with $\mathrm{K}_{\mathrm{p}}=\mathrm{p} / \mathrm{p}^{\circ}\left(\mathrm{A}_{2}\right) /(\mathrm{p}(\mathrm{A}))^{2}$

are often studied. Enthalpy and entropy changes of these reactions are determined, in accordance with second (eq. (4)) and third law (eq. (5)) methods, from the equations:

$\Delta \mathrm{H}_{(\mathrm{T})}^{\circ}=-R \mathrm{~d} \ln \mathrm{K}_{\mathrm{p}(\mathrm{T})} / \mathrm{d}(1 / \mathrm{T})$

$\Delta \mathrm{H}^{\circ}{ }_{(298)}=-\mathrm{T}\left[\mathrm{R} \ln \mathrm{K}_{\mathrm{p}(\mathrm{T})}+\Delta\left(\mathrm{G}^{\circ}{ }_{(\mathrm{T})}-\mathrm{H}^{\circ}{ }_{(298)}\right) / \mathrm{T}\right]$

$\Delta \mathrm{S}_{(\mathrm{T})}^{\circ}=\Delta \mathrm{H}_{(\mathrm{T})}^{\circ} / \mathrm{T}+R \ln \mathrm{K}_{\mathrm{p}(\mathrm{T})}$

Equation (4) is based on the Clausius-Clapeyron equation and its rearrangement leads to a linear form that can be used in an Arrhenius plot ( $\ln \mathrm{K}_{\mathrm{p}}$ versus $\left.1 / \mathrm{T}\right)$ like shown in Fig. (3) to determine the reaction enthalpy in a small temperature range $(\Delta \mathrm{T})$ as the slope $\left(-\Delta \mathrm{H}^{\circ}{ }_{(\mathrm{T})} / R\right)$ of the linear plot.

$\Delta \ln \mathrm{K}_{\mathrm{p}(\mathrm{T})}=-\Delta \mathrm{H}_{(\mathrm{T})}^{\circ} / R \Delta(1 / \mathrm{T})$

This way to obtain reaction enthalpies has the advantage that there is no need to calculate the absolute partial pressures after equation (4) and $\mathrm{k}$ can be neglected. The proportional factor $\mathrm{k}$ is taken always from calibration measurements with all its possible errors, and the ionisation cross-section, also included in the factor, is not always confirmed.

The standard Gibbs energy of reaction is obtained from the equilibrium constant according to the relationship:

$\Delta \mathrm{G}^{\circ}{ }_{(\mathrm{T})}=-R \mathrm{~T} \ln \mathrm{K}_{\mathrm{p}(\mathrm{T})} \quad=\Delta \mathrm{H}^{\circ}{ }_{(\mathrm{T})}-\mathrm{T} \Delta \mathrm{S}^{\circ}{ }_{(\mathrm{T})}$ or to avoid the independently known $\Delta \mathrm{S}^{\circ}(\mathrm{T})$

$=\Delta \mathrm{H}_{(\Theta)}^{\circ}-\mathrm{T} \Delta\left[\left(\mathrm{G}_{(\mathrm{T})}^{\circ}-\mathrm{H}_{(\Theta)}^{\circ}\right) / \mathrm{T}\right]$

$\left(\mathrm{G}^{\circ}{ }_{(\mathrm{T})}-\mathrm{H}_{(\Theta)}\right) / \mathrm{T}$ is the free energy function (fef) and $\Theta$ is the reference temperature usually $0 \mathrm{~K}$ or $298.15 \mathrm{~K}$ depending on the used data base.

Fundamentally, data treatment with the Second and Third Laws of Thermodynamics is equivalent, but the resulting error estimates may be quite different. Other important informations about the condensed phase in a system are the thermodynamic activity $\mathrm{a}_{(\mathrm{i})}$ of its components and the chemical potentials $\mu_{(\mathrm{i})}$ related to these activities.

$\mu_{(\mathrm{i})}=\mu_{(\mathrm{i})}^{\circ}+R \mathrm{~T} \ln \mathrm{a}_{(\mathrm{i})}=\mu^{\circ}{ }_{(\mathrm{i})}+R \mathrm{~T} \ln \left(\mathrm{p}_{(\mathrm{i})} / \mathrm{p}^{\circ}{ }_{(\mathrm{i})}\right)$

$\mathrm{p}(\mathrm{i})$ is the partial pressure of species $i$ in a system and $\mathrm{p}^{\circ}(\mathrm{i})$ the partial pressure of the same species over the pure compound. Different methods to obtain the activity $a_{(i)}$ like the monomer/dimer relation or heterogeneous reactions with one condensed phase or the Gibbs-Duhem integration can be used depending on the matchable measurement conditions.

\section{SKIMMER MS}

The commercial skimmer coupled mass spectrometer with simultaneous thermal analysis (DTA/TG) is shown in Fig. (2) (NETZSCH GmbH, STA409 C). The system consists of two differentially pumped vacuum chambers. Gases entering the $80-\mu \mathrm{m}$ orifice undergo a supersonic free jet expansion into the first chamber, and intermolecular collisions between molecules are decreased drastically, and at that point, the expansion has attained free molecular flow. 

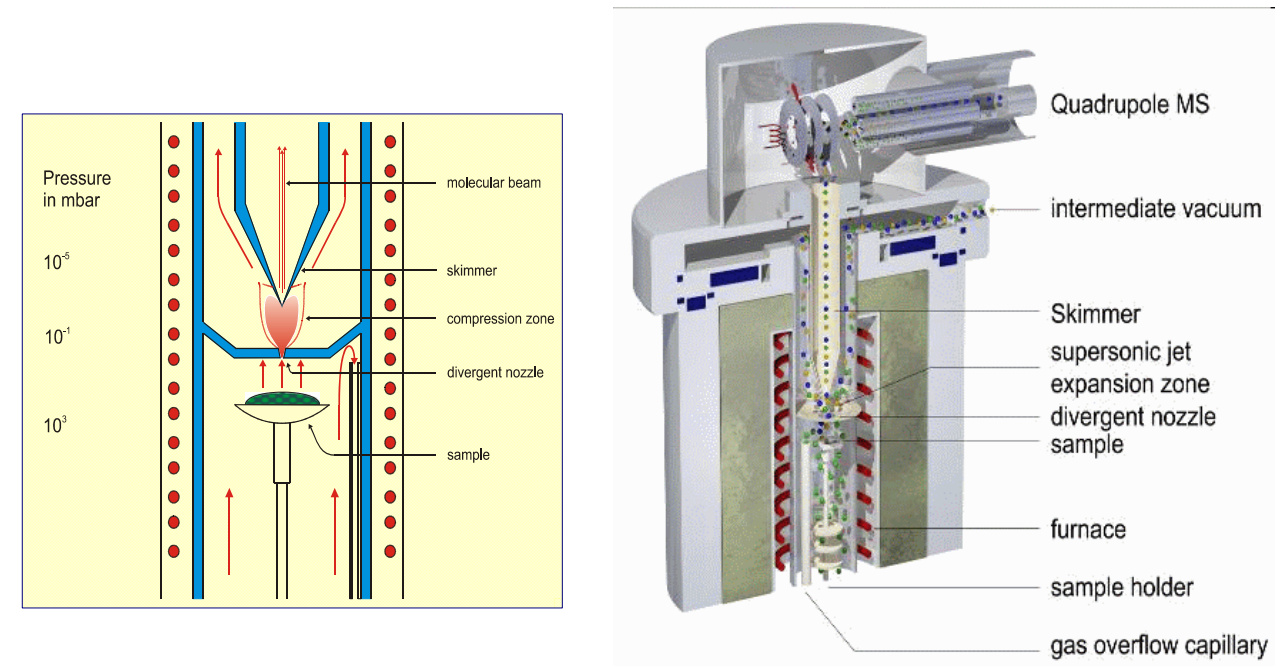

Fig. (2). Skimmer coupled mass spectrometer with simultaneous thermal analysis (DTA/TG) for vapor research (NETZSCH GmbH, STA409 C).

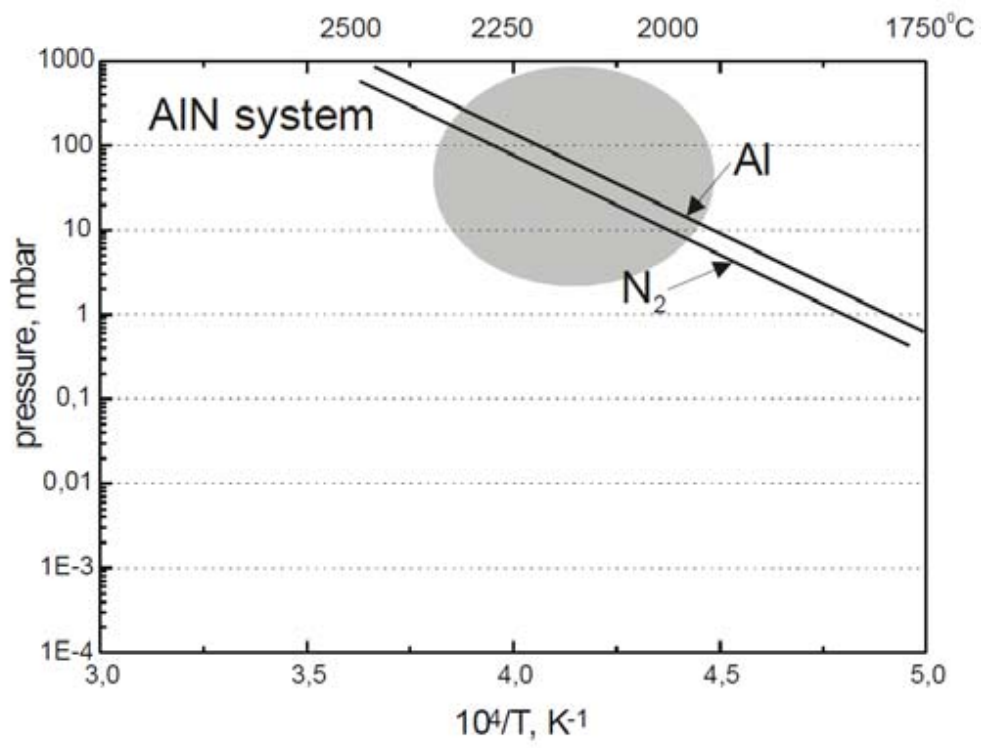

Fig. (3). Partial vapor pressures over AlN. The marked field indicates the relevant temperature and partial pressure region for crystal growth by direct sublimation (Epelbaum et al. [18]).

The interactions between the molecules tend towards ideal behavior. A conical skimmer works as an aperture through which the molecules enter the second stage of the vacuum system as a focused molecular beam. Entering the ion source the molecules are ionized by electron impact ionization with nominal electron energy of $70 \mathrm{eV}$ like in KEMS. The ions are filtered in a quadrupole mass analyzer by their mass-to-charge $(\mathrm{m} / \mathrm{z})$ ratio and the intensity of the ion current is detected by a secondary electron multiplier.

The coupling takes place directly in the furnace and is arranged right above the sample container. Since the entire system has sample temperature, no condensation during the gas emanation changes the condition of the vapor phase of the sample.

The sample holder is adapted to a balance system for a simultaneous registration of the weight. Depending on the construction of the holder it is additionally possible to achieve a DTA signal. Different information like enthalpy changes, decomposition reactions, and the analysis of the decomposition products can be achieved simultaneous.

\section{RESULTS AND DISCUSSION}

KEMS (modified Finnigan MAT 271) measurements on single crystal AlN with grain size of 1-2 mm, $5 \mathrm{~mm}$ bulk, and powder were carried out in a temperature range of 1570 to $1970 \mathrm{~K}$ in a tungsten (W) Knudsen cell. The vapor phase was analyzed and the ions $\mathrm{Al}^{+}, \mathrm{AlO}^{+}, \mathrm{N}_{2}^{+}, \mathrm{N}^{+}, \mathrm{O}_{2}^{+}, \mathrm{O}^{+}, \mathrm{Al}_{2}^{+}$and $\mathrm{Al}_{2} \mathrm{O}^{+}$were registrated in the mass spectrum as representatives of the gas species over AlN (Fig 4, without $\mathrm{AlO}^{+}, \mathrm{Al}_{2}^{+}$).

$\mathrm{Al}_{2} \mathrm{O}^{+}$is the sign for $\mathrm{Al}_{2} \mathrm{O}_{3}$ being an impurity in the bulk either from the crystal growth process or by handling in the atmosphere. The latter is the most dominant way since it was seen that an increasing of the surface led to higher intensities of the oxide containing ions. The $\mathrm{Al}^{+}$ion has precursors (Al) in the condensed phase related to the reactions 


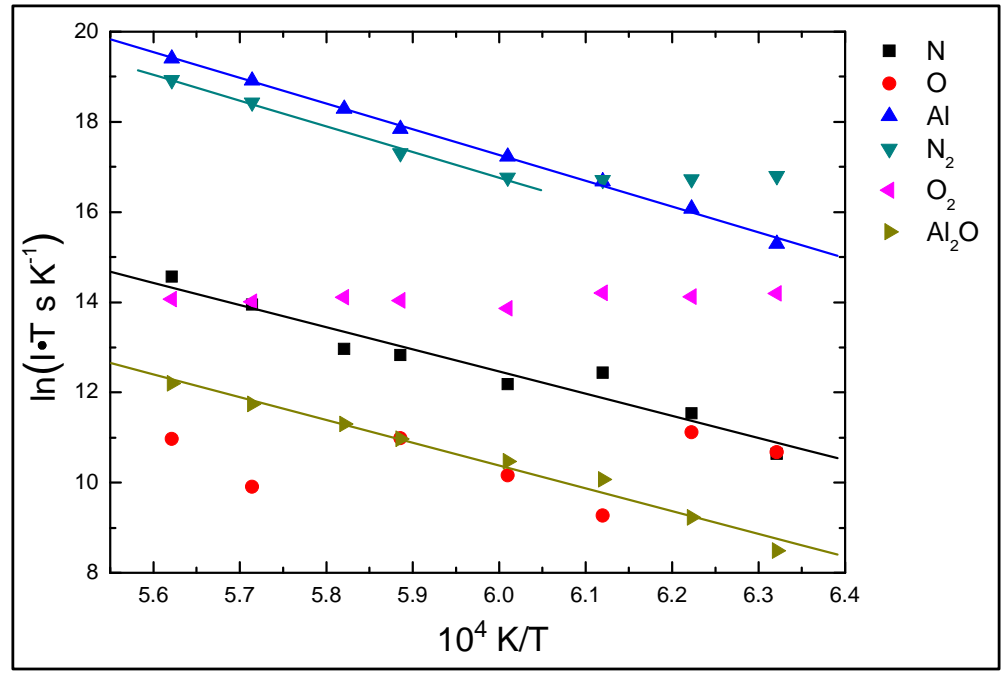

Fig. (4). Ion intensities as a function of the absolute temperature.

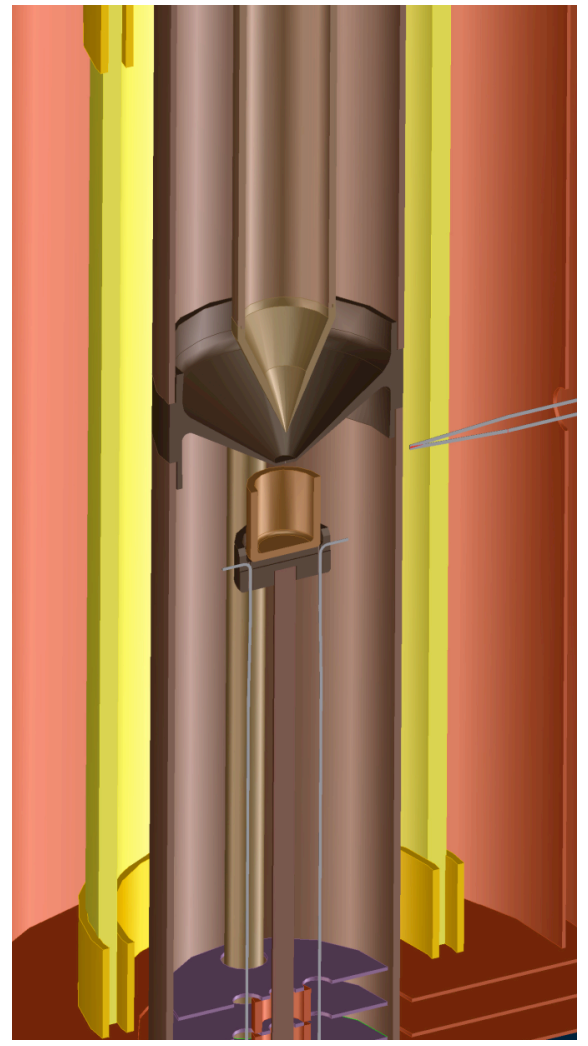

Fig. (5). View inside the core of the CAD-Model of the tungsten based skimmer system with heater, shields, orifice and skimmer.

$\mathrm{Al}_{2} \mathrm{O}_{3}(\mathrm{c})=2 \mathrm{Al}(\mathrm{g})+1.5 \mathrm{O}_{2}$

$\mathrm{Al}_{2} \mathrm{O}_{3}(\mathrm{c})=\mathrm{Al}(\mathrm{g})+\mathrm{AlO}(\mathrm{g})+\mathrm{O}_{2}$

and

$\mathrm{AlN}(\mathrm{c})=\mathrm{Al}(\mathrm{g})+0.5 \mathrm{~N}_{2}(\mathrm{~g})$.

Since the ions of $\mathrm{N}_{2}$ and $\mathrm{Al}$ are most dominant over the crystal of about 8 orders of magnitude higher than $\mathrm{Al}_{2} \mathrm{O}^{+}$, $\mathrm{Al}^{+}$has its roots in AIN (equation (12)).

Gingerich [19] has measured the equilibrium partial pressures of the $\mathrm{Al}_{2} \mathrm{~N}$ molecule and Meloni [20] performed thermodynamic studies of the gaseous molecules $\mathrm{Al}_{2} \mathrm{~N}, \mathrm{AlN}$, and $\mathrm{Al}_{2} \mathrm{~N}_{2}$ both by Knudsen cell mass spectrometry over the $\mathrm{AlN}-\mathrm{Au}$-graphite system. Andrews et al. [21] used infrared matrix isolation spectroscopy to study the products of aluminum atoms reacting with dinitrogen. They identified $\mathrm{AlN}_{2}, \mathrm{Al}_{2} \mathrm{~N}, \mathrm{Al}_{2} \mathrm{~N}_{2}, \mathrm{AlN}_{3}$, and $\mathrm{Al}_{3} \mathrm{~N}$ molecules by nitrogen isotopic substitution and comparison with computed isotopic vibration frequencies.

We could not detect these species neither $\mathrm{Al}_{2} \mathrm{~N}^{+}$, and $\mathrm{Al}_{2} \mathrm{~N}_{2}{ }^{+}$nor the higher complexes molecules described by Andrews [21] and $\mathrm{Li}$ et al. [8] in their first principles prediction of the gas-phase precursors for AlN sublimation growth, even beyond the upper Knudsen conditions between 
$1800 \mathrm{~K}$ and $1970 \mathrm{~K}$. Slack et al. [10] also have excluded the molecule AlN being part of the vapor over $\mathrm{AlN}$. $\mathrm{Al}_{2}{ }^{+}$as a possible fragment of $\mathrm{Al}_{2} \mathrm{~N}$ had a lower intensity than $\mathrm{Al}_{2} \mathrm{O}^{+}$ and they disappeared more and more during the measurements were the impurities of $\mathrm{Al}_{2} \mathrm{O}_{3}$ undergo a cleaning process.

To get some impression about the kinetic orientated vaporization over AIN we did studies with the skimmer coupled mass spectrometer in the some range like the equilibrium studies with KEMS. The vaporization under kinetic conditions with the skimmer has a lower sensitivity detecting ions so nothing more than achieved by KEMS could give additional information clearing the existence of molecules observed by other. Only $\mathrm{NO}^{+}$, due to the presence of the neutral species $\mathrm{NO}$ and $\mathrm{NO}_{2}$ postulated during impurity decomposition of $\mathrm{Al}_{2} \mathrm{O}_{3}$ in nitrogen ambiance was additionally observed.

\section{CONCLUSION}

This article gives an example of investigations at high temperature under both equilibrium and kinetic state.

Processes during the formation of AIN crystal growth are very complex and still today not understood. $\mathrm{Al}_{\mathrm{x}} \mathrm{N}_{\mathrm{y}}(\mathrm{g})$ molecules as determinant forming species could not be observed in our studies. This result favors the classical model of synthesis by sublimation and recombination. Indisputable is the presence of impurities even in highly pure single crystal AIN. Dominant is the process of impurity forming in air and not during the crystal growth since the dependence of an increasing effective surface with grain downsizing could be measured.

A new constructed skimmer coupled mass spectrometer optimized for the conditions of forming single crystal AlN will give possibly information to the still existing unanswered questions.

\section{CONFLICT OF INTEREST}

The authors confirm that this article content has no conflicts of interest.

\section{ACKNOWLEDGEMENT}

Declared none.

\section{REFERENCES}

[1] L. Liu, and J.H. Edgar, "Substrates for gallium nitride epitaxy," Materials Science and Engineering, vol. 37, p. 61, 2002.

[2] J.C. Rojo, L.J. Schowalter, R. Gaska, M. Shur, M.A. Khan, J. Yang, and D.D. Koleske, "Growth and characterization of epitaxial layers on aluminum Nitride substrates prepared from bulk, single crystals," Journal of Crystal Growth, vol. 240, p. 508, 2002.
[3] E.N. Mokhov, O.V. Avdeev, I.S. Barash, T.Yu. Chemekova, A.D. Roenkov, A.S. Segal, A.A. Wolfson, Yu.N. Makarov, M.G. Ramm, and H. Heleva, "Sublimation growth of AlN bulk crystals in Ta crucibles," Journal of Crystal Growth, vol. 281, p. 93, 2005.

[4] M. Bickermann, B.M. Epelbaum, M. Kazan, Z. Herro, P. Masri, and A. Winnacker, "Growth and characterization of bulk AlN substrates grown by PVT, " Physica Status Solidi A, vol. 202, p. $531,2005$.

[5] D. Zhuang, Z.G. Herro, R. Schlesser, B. Raghothamachar, M Dudley, and Z. Sitar, "Chemical vapor deposition of Silicon Carbide epitaxial films and their characterization," Journal of Electronic Material, vol. 35, p. 1513, 2006.

[6] G.A. Slack, R.A. Tanzilli, R.O. Pohl, and J.W. Van der Sande, "The intrinsic thermal conductivity of AlN," Journal of Physical and Chemical Solid, 48, p. 641, 1987.

[7] V.F. Mymrin, K.A. Bulashevich, N.I. Podolskaya, and S.Y. Karpov, "Bandgap engineering of electronic and optoelectronic devices on native AIN and GaN substrates: A modelling insight," Journal of Crystal Growth, vol. 281, p. 115, 2005.

[8] Y. Li, and D.W. Brenner, "First principles prediction of the GasPhase precursors for AlN sublimation growth," Physical Review Letters, vol. 92, no. 7, 075503, 2004.

[9] J.H. Edgar, L. Dua, L. Nyakiti, and J. Chaudhuri, "Native oxide and hydroxides and their implications for bulk AlN crystal growth," Journal of Crystal Growth, vol. 310, pp. 4002- 4006, 2008.

[10] G.A. Slack, and T.F. McNelly, "Growth of high purity AlN crystals," Journal of Crystal Growth, vol. 34, pp. 263-279, 1976.

[11] K. Hilpert, "High temperature mass spectrometry in materials research, in rapid communications in mass spectrometry," vol. 5 pp. 175-187, 1991.

[12] K. Hilpert, "Chemistry of inorganic vapors. Structure and bonding," vol. 73, pp. 97-198, 1990.

[13] P. Clausing, "Über eine Messung der molekularen Geschwindigkeit und eine Prüfung des Kosinusgesetzes," Annalen Der Physik, vol. 7, no. 5, pp. 569-578, 1930.

[14] P. Clausing, "Über die Strömung sehr verdünnter Gase durch Röhren von beliebiger Länge," Annalen Der Physik, vol. 12, no. 8 , pp. 961-989, 1932.

[15] N.A. Gokcen, "Diffusional processes in knudsen cells," Journal of Physical Chemisty, vol. 69, no. 10, pp. 3538-3541, 1965.

[16] M. Knudsen, "The laws of the molecular current and the internal friction current of gases by channels," Annalen Der Physik, vol. vol. 29, no. 1, pp. 75-130, 1909

[17] M. Knudsen, "The molecular current of gases through openings and the effusion," Annalen Der Physik, vol. 29, no. 5, pp. 999$1016,1909$.

[18] B.M. Epelbaum, M. Bickermann, and A. Winnacker, "Seeded PVT growth of aluminum Nitride on Silicon Carbide," Material Science Forum, vol. 433-436, pp. 983-986, 2003.

[19] K. Gingerich, "Mass-Spectrometric determination of heat of atomization of molecules $\mathrm{Al}_{2} \mathrm{~N}$ and $\mathrm{BOCN}$," Journal of the Chemical Society, Chemical Communications, vol. 12, p. 441, 1970.

[20] G. Meloni, and K.A. Gingerich, "Thermodynamic study of the gaseous molecules A12N, AlN, and Al2N2 by Knudsen cell mass spectrometry," Journal of Chemical Physics, vol.113, pp. 10978$11982,2000$.

[21] L. Andrews, M. Zhou, G. V. Chertihin, W.D. Bare, and Y. Hannachi, "Reactions of Laser-Ablated aluminum atoms with Nitrogen atoms and molecules. Infrared spectra and density functional calculations for the AlN 2, $\mathrm{Al} 2 \mathrm{~N}, \mathrm{Al} 2 \mathrm{~N} 2, \mathrm{AlN} 3$, and Al 3 N molecules," Journal of Physical Chemistry, vol. A 104, p. $1656,2000$. 